\title{
cergam
}

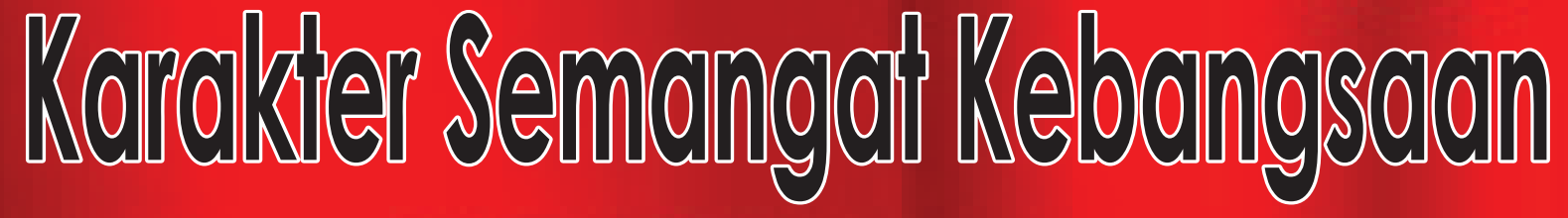

dan Tolepansi

\section{Untuk Anak Usia Dini}

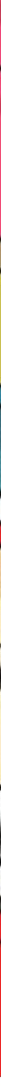

Sekolah Tinggi Theologia Jaffray Makassar

$$
2019
$$




\section{Karakter Semangai Kebangsaan}

dan Toleransi

\section{Untuk Anak Usia Dini}

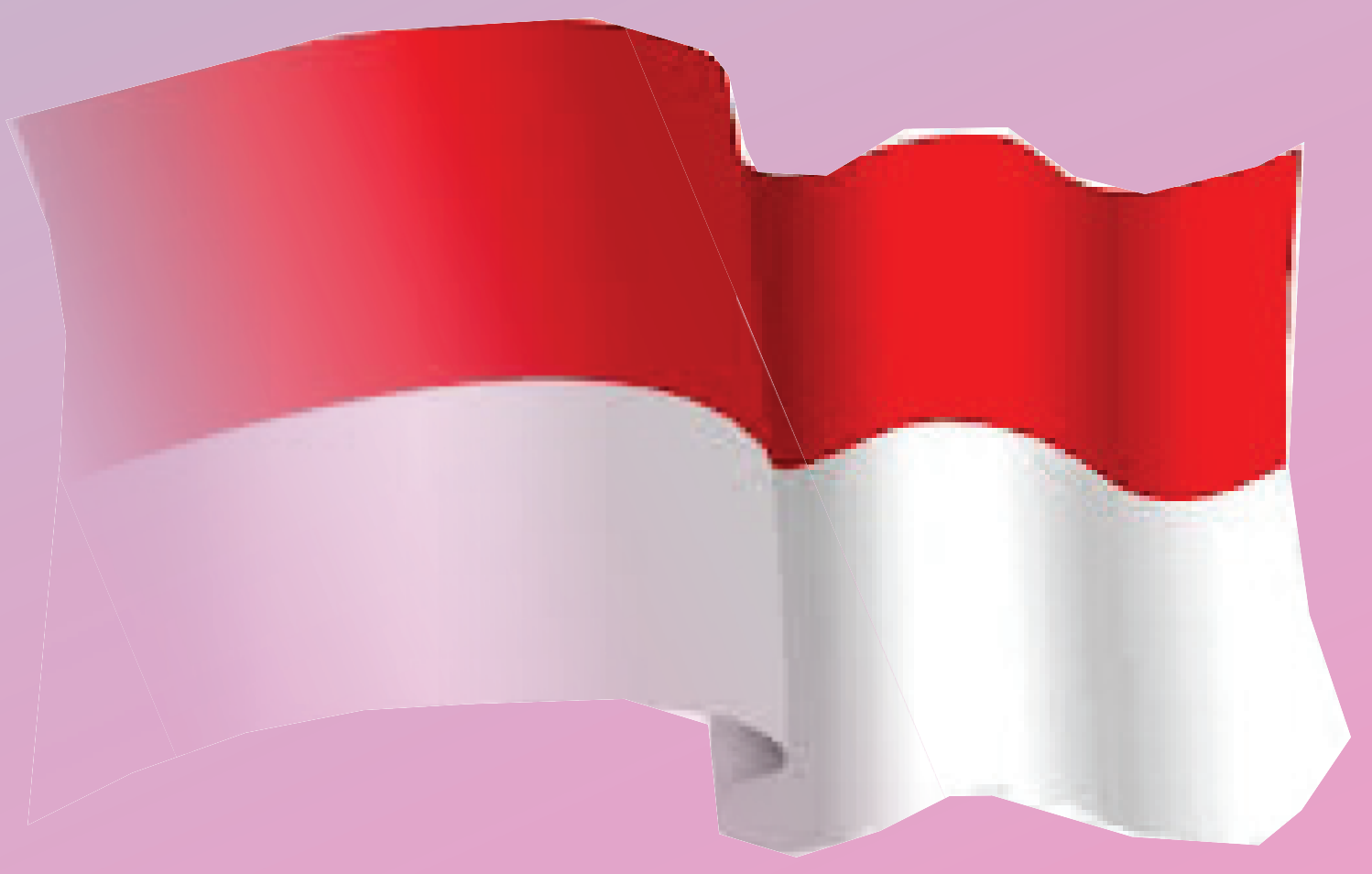

Alamat: Jl. Gunung Merapi No.103 Makassar Sulawesi Selatan, Indonesia. 90114 Email: sttjaffray@yahoo.com

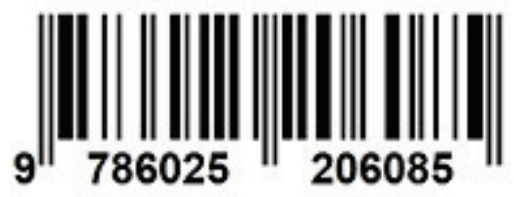


St. Maria Ulfah, M.Pd Hengki Wijaya, M.Th

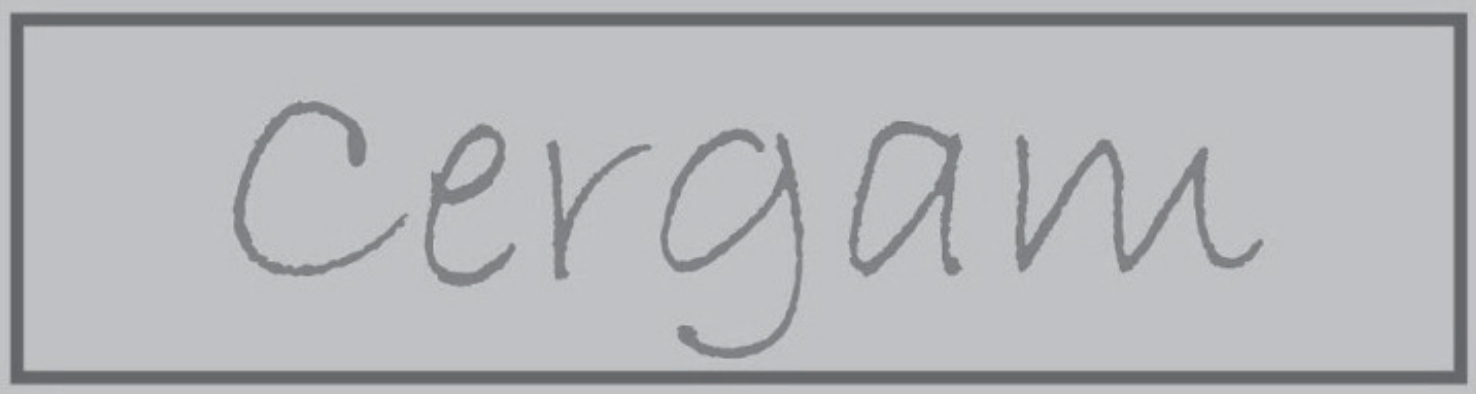

Korrakter Semangari Kebangsaan

\section{dan Toleransi}

\section{Untuk Anak Usia Dini}

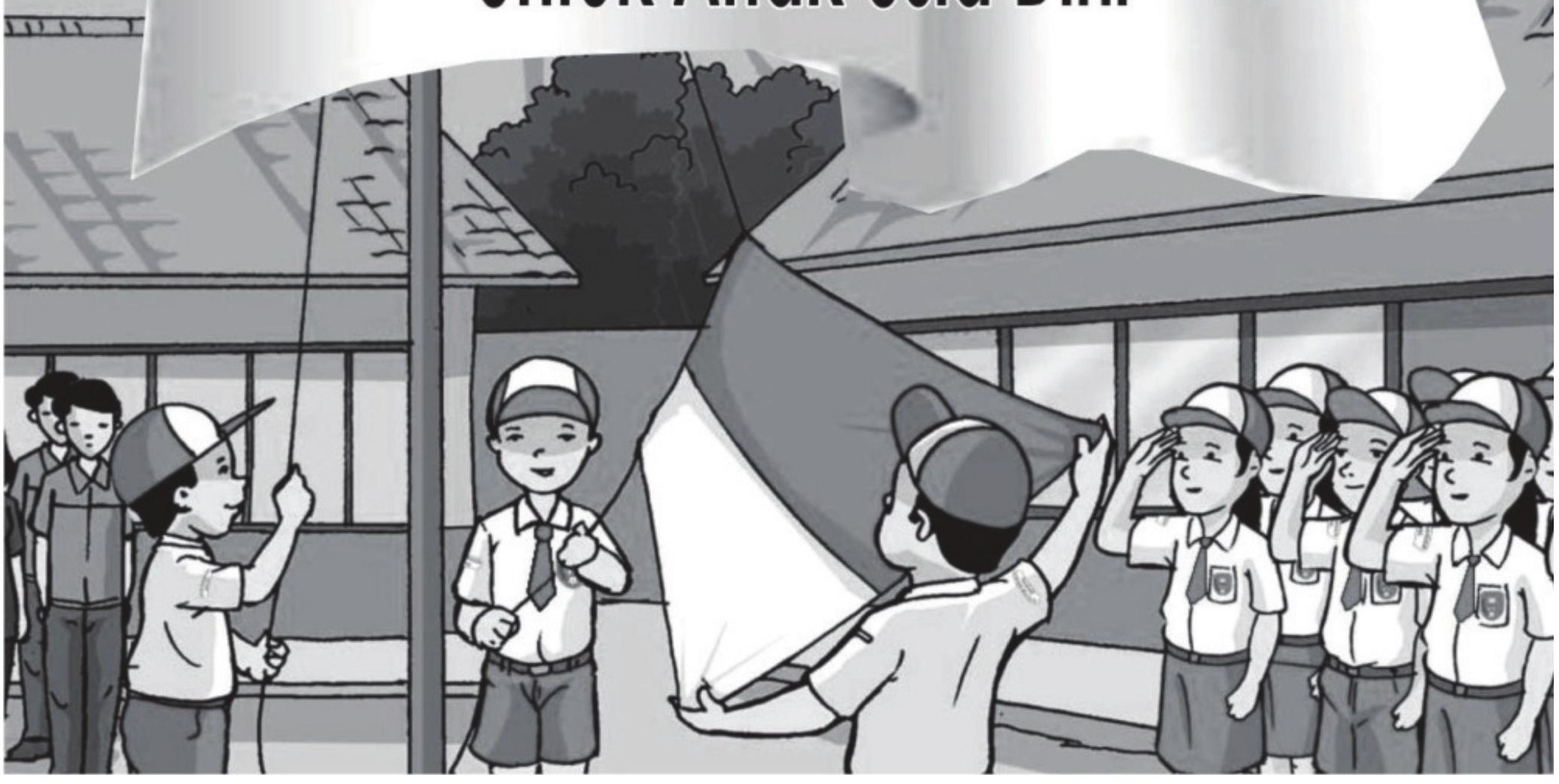

Sekolah Tinggi Theologia Jaffray Makassar 2019

$\Rightarrow+$ dU $\cdots-2=$ 


\title{
ISBN: 978-602-52060-8-5
}

\section{Cergam \\ Karakter Semangat Kebangsaan dan Toleransi Untuk Anak Usia Dini}

\section{Oleh: St. Maria Ulfah, M.Pd Hengki Wijaya, M.Th}

\author{
(C) 2019 Sekolah Tinggi Theologia Jaffray \\ Jalan Gunung Merapi No. 103 Makassar \\ Sulawesi Selatan, Indonesia \\ Telepon : 041 1-3624129 \\ E-mail : sttjaffraymakassar@gmail.com \\ Website: www.sttjaffray.ac.id \\ Penyunting : St. Maria Ulfah \\ Setting/layout: St. Maria Ulfah, Hengki Wijaya \\ Desain Sampul: Hengki Wijaya
}

Dilarang mereproduksi sebagian atau seluruh isi buku ini tanpa izin tertulis dari penulis dan penerbit. 